\title{
MINI-REVIEW
}

\section{Stem Cells in Lung Injury and Repair}

\author{
Felicia Chen* and Alan Fine ${ }^{* \dagger}$
}

From The Pulmonary Center, ${ }^{*}$ Boston University School of Medicine, Boston; and the Division of Pulmonary, Critical Care, and Allergy, ${ }^{\dagger}$ West Roxbury Veteran's Hospital, West Roxbury, Massachusetts

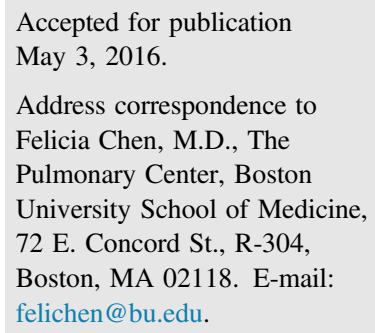

\begin{abstract}
In this review, we summarize the recent literature on the biology of endogenous stem cells in adult lung injury repair. We focus on in vivo studies in mice with an emphasis on data generated using cell-specific Cre-dependent lineage-tracing systems. These studies provide new information on the identification of lung stem cells, their hierarchical relationships, the plasticity of their behavior in different types of injury, and the molecular signals that control their fates. Although most of this work has been on epithelial hierarchies, we expect that further development of robust genetic tools will foster meaningful investigations into how nonepithelial cell populations are controlled during lung injury repair in adults. The ultimate challenge will be to translate these findings to the pathogenesis and treatment of human lung diseases. (Am J Pathol 2016, 186: 2544-2550; http://dx.doi.org/10.1016/j.ajpath.2016.05.023)
\end{abstract}

The adult lung is a complex structure composed of multiple specialized epithelial cell types, two parallel circulations (systemic and pulmonary), two distinct smooth muscle populations (bronchial and vascular), fibroblasts, and a unique local immune system. This complexity is one of the factors that have limited understanding of mechanisms by which lung cells are reconstituted during homeostasis and repair. The recent development of novel lineage-tracing tools and the discovery of informative cell markers have facilitated the clarification of lung progenitor cellular hierarchies. Much of this work has been focused on the epithelium, with less emphasis on other cellular elements in the lung. This reflects the fact that cell-specific lineagetracing systems are better developed for the epithelium. Collectively, these experiments indicate that lung epithelial stem cells are regionally specific. There is no evidence that a single lung stem cell, as in the hematopoietic system, gives rise to all cell lineages during homeostasis or repair. Rather, differentiated epithelia are derived from local epithelial progenitors. Although mesenchymal progenitors in the embryonic mouse lung have regional specificity, ${ }^{1}$ it is unclear whether mesenchymal progenitors in the adult lungs are similarly geographically localized.

The adult lung is a highly quiescent tissue with a remarkably low level of cellular turnover. Recent data indicate that cellular quiescence in the mouse airway epithelium and mesenchyme is an active process mediated by sonic hedgehog signaling. ${ }^{2}$ Although it is not yet clear whether this pathway functions similarly in the human lung, this important observation may be relevant to the pathogenesis of lung diseases characterized by aberrant repair and regeneration.

Historically, understanding how cell turnover and replenishment are regulated has been particularly challenging in the adult lung because of the prolonged quiescence of lung parenchymal cells. Indeed, most of the information learned about the biology of adult lung stem cells came from studies of lung injuries in mice. A further challenge is the fact that there are many morphologically distinct cell types in the lung. At least 40 different cell phenotypes have been described from the trachea to the alveolar space, underscoring the lung's intrinsic complexity.

The increasing interest in this field is based, in large part, on the hope that stem cell-based strategies could be used to reconstitute functional lung tissue in human diseases. In this review, we summarize and highlight recent findings regarding the phenotypes of putative lung stem and progenitor cells and their role in injury repair. Our emphasis is on in vivo studies

Supported by NIH National Heart, Lung, and Blood Institute grants R01 HL116163 (A.F.) and R01 HL130287 (F.C. and A.F.).

This article is part of a review series on lung ontogeny and injury.

Disclosures: None declared. 
that use state-of-the-art genetic models. The review is organized by anatomical location and cell type.

\section{Trachea and Proximal Bronchi}

The mouse trachea and main stem bronchi are lined by a pseudostratified mucociliary epithelium composed of basal cells and three types of differentiated luminal cells (secretory or club, ciliated, and neuroendocrine). Airway basal cells are notable for their expression of TRP63, nerve growth factor receptor, keratin 5 (KRT5), and podoplanin. A subpopulation of basal cells also expresses keratin 14 . In vivo lineage tracing experiments indicate that basal cells comprise approximately equal numbers of stem cells and committed precursors $^{3}$ and give rise to differentiated luminal cells during steady state and epithelial repair. ${ }^{4}$

Lineage tracing using a club cell-specific ScgblalCreER allele reveals that ciliated cells can come from club cells after tracheal injury, ${ }^{5}$ suggesting that club cells are situated between basal cells and ciliated cells in a cellular hierarchy. However, it is also possible that basal cells act through a transient-amplifying cell that differentiates into either club or ciliated cells. Pardo-Saganta et $\mathrm{al}^{6}$ found that after injury two distinct basal cell subpopulations emerge that are defined by expression of the intracellular domain of NOTCH2 (N2ICD; indicative of active Notch2 signaling) or c-MYB (an inhibitor of Notch signaling). Their findings indicate that $\mathrm{N} 2 \mathrm{ICD}^{+}$basal cells directly replenish club cells, whereas c-MYB ${ }^{+}$basal cells directly populate ciliated cells. The central role of the Notch pathway in mediating acquisition of a club cell fate is further underlined by experiments revealing that an increase in Notch activation in basal cells expands the secretory lineage at the expense of the ciliated lineage in vivo. ${ }^{7}$ To date, experimental evidence indicates that ciliated cells are terminally differentiated cells that do not proliferate or give rise to other tracheal epithelial cell types after injury. ${ }^{8}$

Interestingly, after ablation of $\mathrm{KRT}^{+}$basal cells, differentiated club cells can undergo dedifferentiation and replenish lost basal cells; these reconstituted basal cells have the same regenerative properties as the so-called normal basal cells. ${ }^{5,9}$ These observations suggest a greater degree of cellular plasticity than previously recognized in the tracheal epithelium. The implication of this important observation is that differentiated tracheal epithelial cells can undergo adaptive phenotypic switching to ensure proper repair. Notably, mucous-producing goblet cells, which are a key pathological feature of upper airway inflammation in mice, arise from club cells through a distinct genetic program that requires the transcription factor SPDEF. ${ }^{10}$

\section{Distal Airway}

The epithelium of the mouse distal airway is composed of a monolayer of ciliated and secretory cells. $\mathrm{KRT}^{+} / \mathrm{TRP}^{+} 3^{+}$ basal cells are present in this region in humans, but their presence in the uninjured distal airway is not well established in mice. Ciliated cells throughout the airway are marked by expression of the transcription factor FOXJ1 and the cytoskeleton protein TUBB4. In addition, neuroendocrine cells (NECs) are also present and express the transcription factors ASCL1 and PROX1. In contrast to tracheal NECs that are scattered throughout the epithelial surface, the NECs in the distal airways cluster as small aggregates that are situated at airway branching points; these collections of NECs are termed neuroepithelial bodies. Secretory cells, which are also known as club cells, are characterized by the expression of SCGB1A1. Recent data indicate that the club cell phenotype is actively maintained during homeostasis through the interaction of ciliated cell-derived Jagged ligands (JAG1 and JAG2) with the club cell NOTCH2 receptor. ${ }^{11}$ Disruption of this signaling axis at steady state leads to a gain of ciliated cells at the expense of club cells in large and small airways in mice and can reverse goblet cell metaplasia in asthmatic mice. $^{11,12}$

Most of the data regarding regeneration of the epithelium in this region are from studies that use the club cell-specific toxin naphthalene. Exposure to this toxin induces a stereotypic injury response that results in the death and sloughing of most club cells. There exists, however, a subpopulation of club cells that is resistant to naphthalene injury and is characterized by the lack of expression of the cytochrome P450 family member CYP2F2. Such cells are termed variant club cells and are located adjacent to neuroepithelial bodies and at the bronchioalveolar duct junction. ${ }^{13}$ The variant club cells that are located adjacent to neuroepithelial bodies are also marked by UPK3A. ${ }^{14}$

Lineage tracing after naphthalene injury reveals that SCGB1 $1^{+} / \mathrm{CYP} 2 \mathrm{~F} 2^{-}$cells reconstitute the injured epithelium through self-renewal and differentiation into ciliated cells and CYP2F2 ${ }^{+}$club cells, ${ }^{15}$ indicating that variant club cells are epithelial progenitors in small airways after injury. The precise anatomical locations of variant club cells suggest the possibility of a discrete cellular-molecular niche. However, deletion of NECs does not always affect the capacity of variant club cells to regenerate the small airway epithelium after injury. ${ }^{14,16}$ Parabronchial smooth muscle may be essential to variant club cell progenitor function by serving as a source of the fibroblast growth factor $10 .{ }^{17} \mathrm{In}$ mice, deletion of histone deacetylases 1 and 2 in postnatal club cells results in reduced club cell proliferation and persistent loss of the epithelium, indicating that histone deacetylases 1 and 2 are required for small airway epithelial regeneration after naphthalene injury. ${ }^{18}$ In keeping with the phenotypic plasticity of the upper airway epithelium, lineage tracing studies suggest that NECs can give rise to club cells after injury of distal airway epithelium, but tamoxifen persistence may have confounded the results ${ }^{16}$ There is no evidence that ciliated cells in this region have progenitor properties. $^{8}$ 


\section{Bronchioalveolar Duct Junction}

The transition site from bronchioles to alveoli in the mouse is termed the bronchioalveolar duct junction. This region contains a few cells ( $<1$ per bronchioalveolar duct junction) called bronchioalveolar stem cells (BASCs), which co-express SCGB1A1 and SFTPC, a marker of alveolar epithelial type 2 cells (AEC2s). The existence of this cell in the human lung is uncertain because $\mathrm{SCGB} \mathrm{A}^{+} / \mathrm{SFTPC}^{+}$dual positive cells have not been clearly identified in human. Mouse BASCs are resistant to bronchiolar and alveolar damage and proliferate during epithelial cell renewal in vivo. They have been suggested to possess stem cell activity for both small airway and alveolar epithelium, based in large part on in vitro studies. ${ }^{19}$ Using Scgblal-restricted lineage tracing, BASCs did not contribute to the epithelium during homeostasis or alveolar repair after hyperoxia. ${ }^{5}$ In contrast, a similar lineage-tracing strategy identified labeled alveolar epithelial cells after bleomycin injury. ${ }^{20,21}$ Whether these labeled alveolar cells arise from club cells or BASCs is not clear, however, because the Cre allele is active in both cell types. The ability of BASCs to reconstitute injured alveolar epithelium in vivo is further confounded by the fact that some AEC2s express both SCGB1A1 and SFTPC. ${ }^{5}$ Definitive resolution of these issues will require a BASC-specific Cre allele.

WNT signaling appears to play a specialized function in BASC expansion after injury. ${ }^{22}$ However, selective deletion of $\beta$-catenin (CTNNB1) in $S c g b l a 1^{+}$cells did not inhibit club cell regeneration after naphthalene injury, indicating that canonical WNT signaling in BASC and club cells is dispensable for epithelial repair. ${ }^{23}$

\section{Alveolus}

The alveolar epithelium is characterized predominantly by two cell types. The alveolar epithelial type 1 cell (AEC1), which comprises nearly $95 \%$ of the alveolar surface area, is a thin but architecturally complex cell specialized for gas exchange. ${ }^{24}$ These cells express several distinct markers, including podoplanin and aquaporin 5. Recent work indicates that a small subset of AEC1s, characterized by expression of HOPX, may proliferate and give rise to AEC2s after partial pneumonectomy. ${ }^{25}$ However, whether AEC1s self-renew or serve as progenitors in other types of injury remains controversial.

The AEC2 is a cuboidal cell situated at the corners of the alveoli. This cell is notable for the production and packaging of surfactant proteins into lamellar bodies for secretion. A variety of cell-specific markers for AEC2s have been identified, including SFTPC and LYZ2. By using a mouse that expresses an inducible $S f t p c$-driven Cre recombinase, adult AEC2s were found to serve as progenitors for both AEC1s and AEC2s during homeostasis. ${ }^{21}$ During alveolar repair after hyperoxia, bleomycin, or AEC2 ablation, cell turnover is accelerated and characterized by clonal expansion of a distinct subset(s) of AEC2s followed by differentiation into AEC1s. ${ }^{20,21,26}$ Signaling molecules thought to regulate AEC2 self-renewal after injury include epidermal growth factor receptor and oncogene KRAS. ${ }^{26}$ Notably, MMP14 derived from the pulmonary capillary endothelium has been implicated in regenerative alveolarization after pneumonectomy by increasing the bioavailability of epidermal growth factor receptor ligands. ${ }^{27}$

Recent work supports the existence of alternative epithelial stem cell populations in the distal lung. For example, an integrin $\alpha_{6} \beta_{4}$-positive SFTPC-negative alveolar stem cell has been identified and postulated to play a part in reconstituting injured alveolar epithelium. ${ }^{28}$ After severe influenza infection in mice, data suggest the emergence or expansion of distal airway stem cells with reparative properties. In one study, these cells (distal airway stem cells) were found to express the basal cell markers TRP63 and KRT5 and were capable of generating differentiated alveolar and bronchiolar epithelium after injury. ${ }^{29}$ Some of the observations in this study may be confounded, however, by the identification of AEC1s by podoplanin expression, which is also expressed in other lung cell types, including basal cells. In another study, a lineagenegative epithelial progenitor cell was identified that reconstitutes AEC2s and distal airway club cells after severe influenza infection in mice. These cells appear to express KRT5 after activation. ${ }^{30}$ Interestingly, differentiation of lineage-negative epithelial progenitor cells into AEC2s required inhibition of Notch signaling, whereas persistent Notch signaling led to the appearance of cysts reminiscent of honey-combing in human lung fibrosis. ${ }^{30}$ Whether these two studies have identified the same cell type is unclear at this time. Regardless, this is an intriguing area that requires further study.

\section{Fibroblasts and Myofibroblasts}

Historically, there has been significant ambiguity in how fibroblasts and myofibroblasts are defined and distinguished from one another. This reflects, in part, the lack of robust markers that can clearly differentiate these cell types. Both cells are characterized as matrix producing and of mesenchymal origin. Myofibroblasts are largely viewed as being the predominant source of excess connective tissue proteins at sites of lung injury in the proximal and distal airways. They express $\alpha$-actin-2 (alias $\alpha$-smooth muscle actin), a relatively nonspecific intracellular marker. Using a PDRGR $\alpha$-GFP reporter mouse, two transcriptionally distinct populations of resident fibroblasts were identified during lung regeneration after partial pneumonectomy. One population expressed a set of genes suggestive of a matrixor lipo-fibroblast phenotype, whereas the other population expressed a transcriptional profile indicative of a myofibroblast phenotype, ${ }^{31}$ suggesting that myofibroblasts are heterogeneous. Future progress in this area will be aided by use of single-cell RNA sequencing technology.

In view of the importance of myofibroblasts in lung fibrosis, considerable effort has focused on identifying the 
origin of these cells. One hypothesis is that lung myofibroblasts originate from a circulating hematopoietic cell. The findings of bone marrow transplantation studies in mice and humans, however, are inconclusive. ${ }^{32,33}$ During lung allograft rejection in humans, myofibroblasts have been found to be of donor origin. ${ }^{34}$ On the basis of this and other recent data, the general consensus is that myofibroblasts originate from a source within the lung. One possibility put forth is that these cells arise during distal lung injury from AEC2s through an aberrant epithelial-mesenchymal transition event, although this is controversial. In this regard, lineage tracing using an inducible Sftpc-Cre mouse reveals no significant contribution of AEC2s to myofibroblasts after bleomycin injury. ${ }^{20}$ Whether myofibroblasts are derived from resident differentiated cells, such as smooth muscle cells, is not clear because of a lack of informative lineage tracing strategies. Recently, there is evidence that lung myofibroblasts originate from perivascular mesenchymal stem cells (see Pericytes).

Multiple signaling pathways, including transforming growth factor- $\beta$, WNT, vascular endothelial growth factor, and phosphatidylinositol 3-kinase-AKT, have been implicated to promote lung fibrosis in the setting of injury. ${ }^{35}$ One study suggests that fibrotic reactions in the distal lung, which occur in the setting of repetitive injury, involve WNT/ $\beta$-catenin-dependent Notch activation in pericapillary fibroblasts. ${ }^{36}$

\section{Pericytes}

Pericytes are contractile cells that surround capillaries and venules and are notable for being embedded in the endothelial basement membrane. Pericyte markers include proteoglycan CSPG4 (also known as NG2), platelet-derived growth factor- $\beta$ receptor, desmin, $\alpha$-actin- 2 , ATP binding cassette protein $\mathrm{ABCG} 2$, and transcription factor FOXD1. There are data to strongly suggest that these cells are resident mesenchymal stem cells in multiple organs, including lung. ${ }^{37}$

Using a Cspg4-dependent Cre lineage-tagging system, pericytes were found to proliferate but did not contribute to the myofibroblast population that emerged after bleomycin injury ${ }^{20}$; however, pericyte labeling was highly inefficient in this study. On the other hand, using an Abcg2-dependent Cre labeling system, this subpopulation of pericytes was found to contribute to the myofibroblast pool after bleomycin injury. ${ }^{38}$ The expression of ABCG2 in other mesenchymal cell types renders these findings difficult to interpret. Similar findings and limitations are also present in studies using a Foxdl-dependent Cre mouse. ${ }^{39}$ Notably, the downstream sonic hedgehog effector GLI1 marks a population of perivascular cells that express mesenchymal stem cell and pericyte markers. Genetic-labeling and ablation studies found that these cells contribute to myofibroblast pools after lung injury. ${ }^{40}$ Definitive clarification of the stem cell properties and the role of pericytes in lung injury repair will require development of an efficient and specific lineage tracing system.

\section{Smooth Muscle}

Bronchial smooth muscle (BSM) is a highly quiescent tissue during homeostasis. Alterations in BSM mass, however, are a key pathological feature of the asthmatic airway. The relative contributions of hypertrophy and hyperplasia to this alteration in BSM mass are not entirely clear because there are data to support both mechanisms in humans and mice. ${ }^{41}$ Overall, these data are difficult to interpret because the human data are largely derived from autopsy studies of fatal asthma, and the mouse data are derived from disease models of uncertain relevance to human asthma.

Similarly, vascular smooth muscle (VSM) is also highly quiescent. Increase in VSM mass is a key pathological feature in pulmonary artery structure in pulmonary hypertension. ${ }^{42}$ Another feature of vascular remodeling in this disease involves the muscularization of distal pulmonary artery branches that normally are devoid of mural cells. ${ }^{43}$ Several distinct sources of excess VSM in this condition have been proposed. One possibility is that already-differentiated VSM reenters the cell cycle and proliferates in response to an unknown signal. It has also been suggested that a non-VSM source, such as pericyte, endothelial cell, or mesothelial cell, may be contributory. ${ }^{42}$ Recently, investigators have identified in mice a novel VSM progenitor, the primed cell, which is localized at the pulmonary arteriole muscularnonmuscular border. In a murine model of pulmonary hypertension, this cell was found to proliferate, migrate, and establish the pathological muscularization of distal vascular sites. In this work, a specialized role for the transcription factor KLF4 in these VSM progenitors was identified. ${ }^{43}$

\section{Endothelium}

The arterial, capillary, and venous vessels of the lung are lined by endothelial cells. The degree to which cells from these different anatomical sites are similar is not clear. Overall, there is a paucity of knowledge relating to the identification of cells that reconstitute lung endothelium after injury. Whether there are differences in endothelial reparative mechanisms at different levels of the lung's complex vascular network is not known. It is also unclear whether there is a distinct endothelial progenitor population. In this regard, the lack of specific markers has limited the use of lineage-tracing strategies for analysis of endothelial injury in mice. Current consensus is that a circulating endothelial progenitor population that repairs the pulmonary vasculature does not exist. ${ }^{44}$ Some have speculated that the injured endothelium is replaced through a process that involves proliferation of neighboring, differentiated endothelial cells, whereas others have postulated the existence of a local endothelial progenitor. ${ }^{42}$ Data pointing to a progenitor 
Table 1 Identity and Location of Putative Stem Cell Populations Mediating Tissue Repair

\begin{tabular}{|c|c|c|c|c|c|}
\hline Tissue and region & Stem cell & Marker genes & Daughter cells & Key signals & References \\
\hline \multirow[t]{2}{*}{$\begin{array}{l}\text { Trachea and } \\
\text { proximal airway }\end{array}$} & Basal cell & $\begin{array}{l}T_{R P 63^{+}}, K_{R T 5^{+}}, \mathrm{NGFR}^{+}, \\
\mathrm{PDPN}^{+}, \mathrm{KRT14}^{+}\end{array}$ & Ciliated, club, self & $\mathrm{NOTCH}$ & $4,6,7$ \\
\hline & Club cell & $S C G B 1 A 1^{+}, \mathrm{CYP}_{2} \mathrm{~F}^{+}$ & $\begin{array}{l}\text { Basal, ciliated, goblet, } \\
\text { self }\end{array}$ & NOTCH, SPDEF, HDAC1/2 & $5,9,10,17$ \\
\hline \multirow[t]{4}{*}{ Distal airway } & Variant club cell & $\mathrm{SCGB}_{1 A 1^{+}}{ }^{+} \mathrm{CYP} 2 \mathrm{~F} 2^{-}, \mathrm{UPK} 3 A^{+}$ & Ciliated, club, self & N0TCH, FGF10 & $15,17,18$ \\
\hline & NEC & $\mathrm{ASCL1}^{+}, \mathrm{CGRP}^{+}, \mathrm{PROX}^{+}$ & Ciliated, club, self & ? & 16 \\
\hline & DASC & $\operatorname{TRP63}^{+}, \mathrm{KRT5}^{+}, \mathrm{KRT6}^{+}$ & AEC2, club, self, AEC1? & ? & 29 \\
\hline & LNEP & $\begin{array}{l}\text { ITGA6 }{ }^{+}, \text {ITGB }^{+}, \text {SFTPC } \\
\text { SCGB1A1 }\end{array}$ & $\mathrm{AEC2}$, club, self & $\mathrm{NOTCH}$ & 30 \\
\hline BADJ & BASC & SFTPC $^{+}$, SCGB1A1 $^{+}$ & Self, club? AEC2? & WNT & $19-22$ \\
\hline \multirow[t]{3}{*}{ Alveolus } & $\mathrm{AEC} 2$ & SFTPC ${ }^{+}, \mathrm{LYZ2}^{+}$ & AEC1, self & WNT, EGFR-KRAS & $20,26,27$ \\
\hline & AEC1 & $H O P X^{+}, A Q P 5^{+}, P D P N^{+}$ & AEC2, self & TGF $\beta$ & 25 \\
\hline & $\begin{array}{l}\mathrm{ITGA}^{+}{ }^{+} \mathrm{ITGB}^{+}{ }^{+} \mathrm{SFTPC}^{-} \\
\text {AEC }\end{array}$ & $\begin{array}{l}I T G A 6^{+},{I T G B 4^{+}}^{+}, \text {SFTPC } \\
\quad \text { SCGB1A1 }\end{array}$ & AEC1, AEC2, club, self & $?$ & 28 \\
\hline Mesenchyme & Pericyte & $\begin{array}{l}\text { CSPG4 }{ }^{+}, \mathrm{ABCG}^{+}, \mathrm{PDGFR}^{+}, \\
\quad \mathrm{FOXD1}^{+}, \mathrm{GLI1}^{+}\end{array}$ & Myofibroblast, self & $\begin{array}{l}\text { SHH, WNT-NOTCH, TGF } \beta \text {, } \\
\text { VEGF, PI3K-AKT }\end{array}$ & $35-40$ \\
\hline Endothelium & Endothelial cell & TIE2 $^{+}$ & Myofibroblast & TGF $\beta$ & 47 \\
\hline VSMC & Primed cell & $\begin{array}{l}\mathrm{ACTA}^{+}, \mathrm{MYH}_{1} 1^{+}, \mathrm{PDGFR}^{+} \\
\quad \mathrm{KLF}^{+}\end{array}$ & VSMC, self & PDGF-KLF4 & 43 \\
\hline
\end{tabular}

?, unknown; AEC, alveolar epithelial cell; AEC1, type 1 alveolar epithelial cell; AEC2, type 2 alveolar epithelial cell; AKT, protein kinase B; BADJ, bronchioalveolar duct junction; BASC, bronchioalveolar stem cell; DASC, distal airway stem cell; EGFR, epidermal growth factor receptor; FGF10, fibroblast growth factor 10; HDAC, histone deacetylase; KLF4, Kruppel-like factor 4; KRAS, Kirsten rat sarcoma viral oncogene homolog; LNEP, lineage-negative epithelial progenitor; NEC, neuroendocrine cell; PDGF, platelet-derived growth factor; PI3K, phosphoinositide 3-kinase; SHH, sonic hedgehog; SPDEF, SAM pointed domain containing ETS transcription factor; TGF $\beta$, transforming growth factor beta; VEGF, vascular endothelial growth factor; VSMC, vascular smooth muscle cell; WNT, wingless-type MMTV integration site family.

population largely rest, however, on observations in which isolated $\mathrm{KDR}^{+}$cell populations that express putative stem cell markers (CD34 and CD133) exhibit morphologic and molecular characteristics of mature endothelial cells after stimulation in culture. ${ }^{45}$ The lack of standardized isolation procedures and functional assays are limiting issues for this field.
There are data suggesting that endothelial cells undergo an endothelial-to-mesenchymal transition in pathological lung conditions. For instance, the presence of cells coexpressing endothelial and smooth muscle markers in lung sections from patients with pulmonary hypertension raises the possibility that endothelial cells contribute to the excess VSM that characterizes this disease. ${ }^{46}$ In addition,

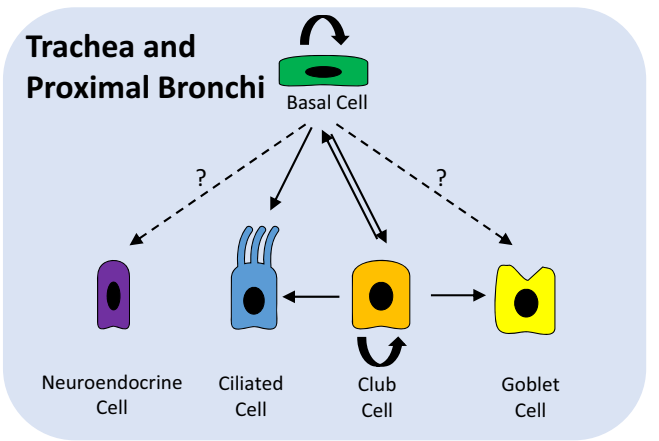

Figure 1 Epithelial stem cells of the mouse lung and their response to injury. Arrows indicate cells that have been suggested by lineage-tracing techniques to generate the indicated lineages after injury. Solid arrows represent lineages that are generally accepted, whereas dotted arrows with question marks are speculative lineages. Curved arrows represent selfrenewal.

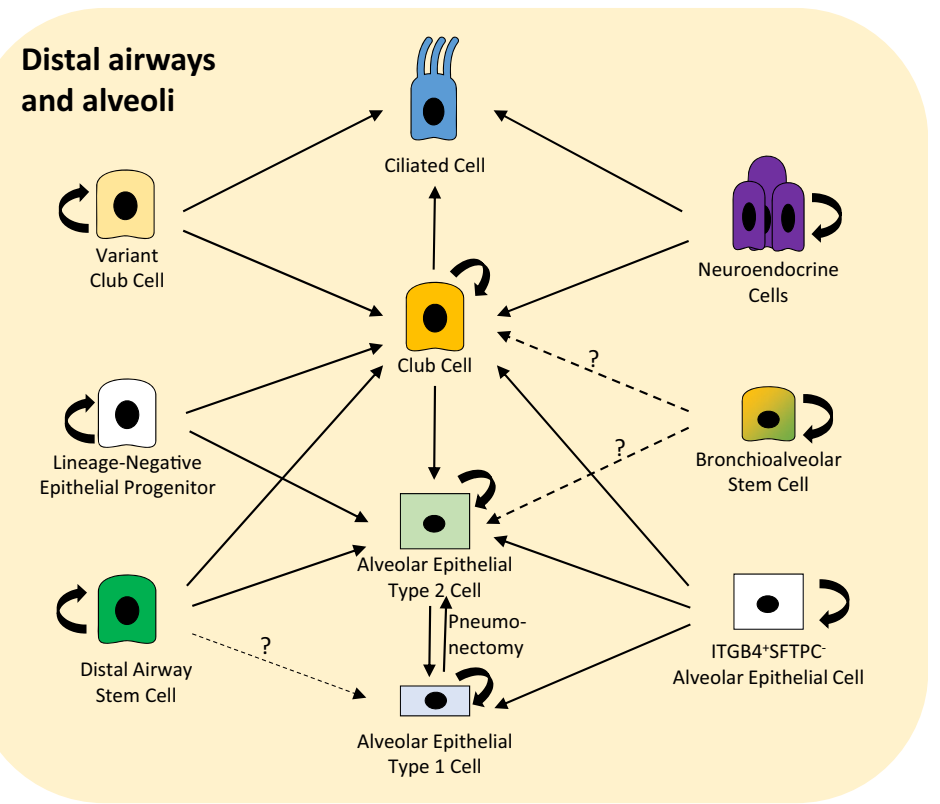


myofibroblasts in bleomycin lung injury were found to be derived from a TIE2-expressing population in mice. ${ }^{47}$ This latter finding, however, does not definitively establish a role for endothelial-to-mesenchymal transition in lung fibrosis because the expression of the Tie 2 gene is not endothelium specific.

\section{Mesothelium}

The fetal mesothelium serves as a source of mesenchymal progenitor cells for differentiated BSMs, VSMs, and peribronchial fibroblasts in the developing lung. ${ }^{48,49}$ In contrast, the adult mesothelium does not contribute to the accumulation of myofibroblasts or smooth muscle that characterizes several specific mouse models of lung disease and injury. ${ }^{50}$ Whether there are conditions where the adult lung mesothelium contributes to repair remains unclear at this time.

\section{Conclusion}

In the past decade, there have been considerable advances in our understanding of progenitor cells and their hierarchical relationships, particularly in the epithelial compartments of the lung during injury repair (Table 1 and Figure 1). These advances have been largely attributable to the development of vigorous lineage-tracing systems that support investigations into the turnover and differentiation of the lung epithelium. In contrast, a lack of cell-specific markers and genetic tools has limited our knowledge of the progenitor populations that sustain and regulate the nonepithelial components of the lung. In the future, we expect that further development of robust genetic tools will not only deepen our understanding of lung epithelial stem cells but also foster more meaningful investigations into how nonepithelial cell populations are controlled during lung injury repair. Additional studies in this field should also enhance our understanding of cellular plasticity and the role of recently and yet to be identified novel stem cell populations in lung regeneration. The translational significance of the findings in mice must be considered with caution, however, in view of the significant differences in lung structure between mouse and human and the questionable relevance of murine models to human diseases. A major challenge for the field is thus figuring out how all this work relates to the pathogenesis and treatment of human lung disease.

\section{References}

1. Kumar ME, Bogard PE, Espinoza FH, Menke DB, Kingsley DM, Krasnow MA: Mesenchymal cells: defining a mesenchymal progenitor niche at single-cell resolution. Science 2014, 346:1258810

2. Peng T, Frank DB, Kadzik RS, Morley MP, Rathi KS, Wang T, Zhou S, Cheng L, Lu MM, Morrisey EE: Hedgehog actively maintains adult lung quiescence and regulates repair and regeneration. Nature 2015, 526:578-582
3. Watson JK, Rulands S, Wilkinson AC, Wuidart A, Ousset M, Van Keymeulen A, Gottgens B, Blanpain C, Simons BD, Rawlins EL: Clonal dynamics reveal two distinct populations of basal cells in slow-turnover airway epithelium. Cell Rep 2015, 12:90-101

4. Rock JR, Onaitis MW, Rawlins EL, Lu Y, Clark CP, Xue Y, Randell SH, Hogan BL: Basal cells as stem cells of the mouse trachea and human airway epithelium. Proc Natl Acad Sci U S A 2009, 106: 12771-12775

5. Rawlins EL, Okubo T, Xue Y, Brass DM, Auten RL, Hasegawa H, Wang F, Hogan BL: The role of Scgbla1+ Clara cells in the long-term maintenance and repair of lung airway, but not alveolar, epithelium. Cell Stem Cell 2009, 4:525-534

6. Pardo-Saganta A, Law BM, Tata PR, Villoria J, Saez B, Mou H, Zhao R, Rajagopal J: Injury induces direct lineage segregation of functionally distinct airway basal stem/progenitor cell subpopulations. Cell Stem Cell 2015, 16:184-197

7. Rock JR, Gao X, Xue Y, Randell SH, Kong YY, Hogan BL: Notchdependent differentiation of adult airway basal stem cells. Cell Stem Cell 2011, 8:639-648

8. Rawlins EL, Hogan BL: Ciliated epithelial cell lifespan in the mouse trachea and lung. Am J Physiol Lung Cell Mol Physiol 2008, 295: L231-L234

9. Tata PR, Mou H, Pardo-Saganta A, Zhao R, Prabhu M, Law BM, Vinarsky V, Cho JL, Breton S, Sahay A, Medoff BD, Rajagopal J: Dedifferentiation of committed epithelial cells into stem cells in vivo. Nature 2013, 503:218-223

10. Chen G, Korfhagen TR, Xu Y, Kitzmiller J, Wert SE, Maeda Y, Gregorieff A, Clevers H, Whitsett JA: SPDEF is required for mouse pulmonary goblet cell differentiation and regulates a network of genes associated with mucus production. J Clin Invest 2009, 119: 2914-2924

11. Lafkas D, Shelton A, Chiu C, de Leon Boenig G, Chen Y, Stawicki SS, Siltanen C, Reichelt M, Zhou M, Wu X, Eastham-Anderson J, Moore H, Roose-Girma M, Chinn Y, Hang JQ, Warming S, Egen J, Lee WP, Austin C, Wu Y, Payandeh J, Lowe JB, Siebel CW: Therapeutic antibodies reveal Notch control of transdifferentiation in the adult lung. Nature 2015, 528:127-131

12. Danahay H, Pessotti AD, Coote J, Montgomery BE, Xia D, Wilson A, Yang H, Wang Z, Bevan L, Thomas C, Petit S, London A, LeMotte P, Doelemeyer A, Velez-Reyes GL, Bernasconi P, Fryer CJ, Edwards M, Capodieci P, Chen A, Hild M, Jaffe AB: Notch2 is required for inflammatory cytokine-driven goblet cell metaplasia in the lung. Cell Rep 2015, 10:239-252

13. Giangreco A, Reynolds SD, Stripp BR: Terminal bronchioles harbor a unique airway stem cell population that localizes to the bronchoalveolar duct junction. Am J Pathol 2002, 161:173-182

14. Guha A, Vasconcelos M, Cai Y, Yoneda M, Hinds A, Qian J, Li G, Dickel L, Johnson JE, Kimura S, Guo J, McMahon J, McMahon AP, Cardoso WV: Neuroepithelial body microenvironment is a niche for a distinct subset of Clara-like precursors in the developing airways. Proc Natl Acad Sci U S A 2012, 109: 12592-12597

15. Hong KU, Reynolds SD, Giangreco A, Hurley CM, Stripp BR: Clara cell secretory protein-expressing cells of the airway neuroepithelial body microenvironment include a label-retaining subset and are critical for epithelial renewal after progenitor cell depletion. Am J Respir Cell Mol Biol 2001, 24:671-681

16. Song H, Yao E, Lin C, Gacayan R, Chen MH, Chuang PT: Functional characterization of pulmonary neuroendocrine cells in lung development, injury, and tumorigenesis. Proc Natl Acad Sci U S A 2012, 109:17531-17536

17. Volckaert T, Dill E, Campbell A, Tiozzo C, Majka S, Bellusci S, De Langhe SP: Parabronchial smooth muscle constitutes an airway epithelial stem cell niche in the mouse lung after injury. J Clin Invest 2011, 121:4409-4419

18. Wang Y, Tian Y, Morley MP, Lu MM, Demayo FJ, Olson EN, Morrisey EE: Development and regeneration of Sox $2+$ endoderm 
progenitors are regulated by a Hdac1/2-Bmp4/Rb1 regulatory pathway. Dev Cell 2013, 24:345-358

19. Kim CF, Jackson EL, Woolfenden AE, Lawrence S, Babar I, Vogel S, Crowley D, Bronson RT, Jacks T: Identification of bronchioalveolar stem cells in normal lung and lung cancer. Cell 2005, 121:823-835

20. Rock JR, Barkauskas CE, Cronce MJ, Xue Y, Harris JR, Liang J, Noble PW, Hogan BL: Multiple stromal populations contribute to pulmonary fibrosis without evidence for epithelial to mesenchymal transition. Proc Natl Acad Sci U S A 2011, 108:E1475-E1483

21. Barkauskas CE, Cronce MJ, Rackley CR, Bowie EJ, Keene DR, Stripp BR, Randell SH, Noble PW, Hogan BL: Type 2 alveolar cells are stem cells in adult lung. J Clin Invest 2013, 123:3025-3036

22. Zhang Y, Goss AM, Cohen ED, Kadzik R, Lepore JJ, Muthukumaraswamy K, Yang J, DeMayo FJ, Whitsett JA, Parmacek MS, Morrisey EE: A Gata6-Wnt pathway required for epithelial stem cell development and airway regeneration. Nat Genet 2008, 40:862-870

23. Zemke AC, Teisanu RM, Giangreco A, Drake JA, Brockway BL, Reynolds SD, Stripp BR: Beta-catenin is not necessary for maintenance or repair of the bronchiolar epithelium. Am J Respir Cell Mol Biol 2009, 41:535-543

24. Weibel ER: On the tricks alveolar epithelial cells play to make a good lung. Am J Respir Crit Care Med 2015, 191:504-513

25. Jain R, Barkauskas CE, Takeda N, Bowie EJ, Aghajanian H, Wang Q, Padmanabhan A, Manderfield LJ, Gupta M, Li D, Li L, Trivedi CM, Hogan BL, Epstein JA: Plasticity of Hopx(+) type I alveolar cells to regenerate type II cells in the lung. Nat Commun 2015, 6:6727

26. Desai TJ, Brownfield DG, Krasnow MA: Alveolar progenitor and stem cells in lung development, renewal and cancer. Nature 2014, 507:190-194

27. Ding BS, Nolan DJ, Guo P, Babazadeh AO, Cao Z, Rosenwaks Z, Crystal RG, Simons M, Sato TN, Worgall S, Shido K, Rabbany SY, Rafii S: Endothelial-derived angiocrine signals induce and sustain regenerative lung alveolarization. Cell 2011, 147:539-553

28. Chapman HA, Li X, Alexander JP, Brumwell A, Lorizio W, Tan K, Sonnenberg A, Wei Y, Vu TH: Integrin alpha6beta4 identifies an adult distal lung epithelial population with regenerative potential in mice. J Clin Invest 2011, 121:2855-2862

29. Zuo W, Zhang T, Wu DZ, Guan SP, Liew AA, Yamamoto Y, Wang X, Lim SJ, Vincent M, Lessard M, Crum CP, Xian W, McKeon F: p63(+)Krt5(+) distal airway stem cells are essential for lung regeneration. Nature 2015, 517:616-620

30. Vaughan AE, Brumwell AN, Xi Y, Gotts JE, Brownfield DG, Treutlein B, Tan K, Tan V, Liu FC, Looney MR, Matthay MA, Rock JR, Chapman HA: Lineage-negative progenitors mobilize to regenerate lung epithelium after major injury. Nature 2015, 517:621-625

31. Green J, Endale M, Auer H, Perl AT: Diversity of interstitial lung fibroblasts is regulated by PDGFRalpha kinase activity. Am J Respir Cell Mol Biol 2016, 54:532-545

32. Hashimoto N, Jin H, Liu T, Chensue SW, Phan SH: Bone marrowderived progenitor cells in pulmonary fibrosis. J Clin Invest 2004, 113:243-252

33. Cilloni D, Carlo-Stella C, Falzetti F, Sammarelli G, Regazzi E, Colla S, Rizzoli V, Aversa F, Martelli MF, Tabilio A: Limited engraftment capacity of bone marrow-derived mesenchymal cells following T-cell-depleted hematopoietic stem cell transplantation. Blood 2000, 96:3637-3643

34. Lama VN, Smith L, Badri L, Flint A, Andrei AC, Murray S, Wang Z, Liao H, Toews GB, Krebsbach PH, Peters-Golden M, Pinsky DJ, Martinez FJ, Thannickal VJ: Evidence for tissue-resident mesenchymal stem cells in human adult lung from studies of transplanted allografts. J Clin Invest 2007, 117:989-996

35. Yan Z, Kui Z, Ping Z: Reviews and prospectives of signaling pathway analysis in idiopathic pulmonary fibrosis. Autoimmun Rev 2014, 13:1020-1025

36. Cao ZW, Lis R, Ginsberg M, Chayez D, Shido K, Rabbany SY, Fong GH, Sakmar TP, Rafii S, Ding BS: Targeting of the pulmonary capillary vascular niche promotes lung alveolar repair and ameliorates fibrosis. Nat Med 2016, 22:154-162

37. Wong SP, Rowley JE, Redpath AN, Tilman JD, Fellous TG, Johnson JR: Pericytes, mesenchymal stem cells and their contributions to tissue repair. Pharmacol Ther 2015, 151:107-120

38. Marriott S, Baskir RS, Gaskill C, Menon S, Carrier EJ, Williams J, Talati M, Helm K, Alford CE, Kropski JA, Loyd J, Wheeler L, Johnson J, Austin E, Nozik-Grayck E, Meyrick B, West JD, Klemm DJ, Majka SM: ABCG2pos lung mesenchymal stem cells are a novel pericyte subpopulation that contributes to fibrotic remodeling. Am J Physiol Cell Physiol 2014, 307:C684-C698

39. Hung C, Linn G, Chow YH, Kobayashi A, Mittelsteadt K, Altemeier WA, Gharib SA, Schnapp LM, Duffield JS: Role of lung pericytes and resident fibroblasts in the pathogenesis of pulmonary fibrosis. Am J Respir Crit Care Med 2013, 188:820-830

40. Kramann R, Schneider RK, DiRocco DP, Machado F, Fleig S, Bondzie PA, Henderson JM, Ebert BL, Humphreys BD: Perivascular Gli1+ progenitors are key contributors to injury-induced organ fibrosis. Cell Stem Cell 2015, 16:51-66

41. Ozier A, Allard B, Bara I, Girodet PO, Trian T, Marthan R, Berger P: The pivotal role of airway smooth muscle in asthma pathophysiology. J Allergy 2011, 2011:742710

42. Baskir R, Majka S: Pulmonary vascular remodeling by resident lung stem and progenitor cells. Lung Stem Cells in the Epithelium and Vasculature. Edited by Firth A, Yuan JXJ. New York: Springer International Publishing, 2015, pp. 221-240

43. Sheikh AQ, Misra A, Rosas IO, Adams RH, Greif DM: Smooth muscle cell progenitors are primed to muscularize in pulmonary hypertension. Sci Transl Med 2015, 7:308ra159

44. Ohle SJ, Anandaiah A, Fabian AJ, Fine A, Kotton DN: Maintenance and repair of the lung endothelium does not involve contributions from marrow-derived endothelial precursor cells. Am J Respir Cell Mol Biol 2012, 47:11-19

45. Firth AL, Yuan JX: Identification of functional progenitor cells in the pulmonary vasculature. Pulm Circ 2012, 2:84-100

46. Good RB, Gilbane AJ, Trinder SL, Denton CP, Coghlan G, Abraham DJ, Holmes AM: Endothelial to mesenchymal transition contributes to endothelial dysfunction in pulmonary arterial hypertension. Am J Pathol 2015, 185:1850-1858

47. Hashimoto N, Phan SH, Imaizumi K, Matsuo M, Nakashima H, Kawabe T, Shimokata K, Hasegawa Y: Endothelial-mesenchymal transition in bleomycin-induced pulmonary fibrosis. Am J Respir Cell Mol Biol 2010, 43:161-172

48. Que J, Wilm B, Hasegawa H, Wang F, Bader D, Hogan BL: Mesothelium contributes to vascular smooth muscle and mesenchyme during lung development. Proc Natl Acad Sci U S A 2008, 105: 16626-16630

49. Dixit R, Ai X, Fine A: Derivation of lung mesenchymal lineages from the fetal mesothelium requires hedgehog signaling for mesothelial cell entry. Development 2013, 140:4398-4406

50. von Gise A, Stevens SM, Honor LB, Oh JH, Gao C, Zhou B, Pu WT: Contribution of fetal but not adult pulmonary mesothelium to mesenchymal lineages in lung homeostasis and fibrosis. Am J Respir Cell Mol Biol 2016, 54:222-230 